\title{
PRAGMATISMO Y DERECHO: EL CASO DE LA FILOSOFÍA DE JOHN DEWEY
}

\section{PRAGMATISM AND LAW: THE CASE OF JOHN DEWEY'S PHILOSOPHY}

\author{
OMAR GARCía LunA* \\ Universidad Veracruzana, México \\ jpf.og1@gmail.com
}

\section{RESUMEN:}

En el presente trabajo se repasan los aportes de John Dewey a la filosofía del derecho, y se exploran algunas vetas de reflexión que se desprende de la filosofía pragmatista de este autor. Se hace notar que la filosofía contemporánea tiene una fuerte ascendiente pragmatista que no siempre es reconocida. Al mismo tiempo, este ensayo puede ser visto como un esfuerzo de divulgar el pensamiento de un filósofo que está considerado por muchos entre los mejores del siglo XX, pero cuyo trabajo es escasamente conocido en el ámbito latinoamericano.

\section{Palabras clave:}

John Dewey, pragmatismo, filosofía del derecho, democracia.

\section{ABSTRACT:}

In the present work, John Dewey's contributions to the philosophy of law are reviewed, and some veins of reflection that emerge from this author's pragmatist philosophy are explored. It is noted that contemporary philosophy has a strong pragmatist ascendancy that is not always recognized. At the same time, this essay can be seen as an effort to disseminate the thought of a philosopher who is considered by many to be among the best of the 20th century, but whose work is scarcely known in Latin America.

Keywords:

John Dewey, pragmatism, philosophy of law, democracy.

* Doctor en Filosofía por la Universidad Veracruzana. 
SUMARIO: Introducción; 1. Breve semblanza biográfica y filosófica de John Dewey; 2. La filosofía del derecho en la obra de John Dewey; 3. La teoría de la valoración de John Dewey y las relaciones entre derecho y moral; 4. Democracia, libertad y derechos en el pensamiento de John Dewey; Consideraciones finales.

\section{INTRODUCCIÓN}

En las últimas décadas ha tenido lugar un movimiento de renovación en los estudios filosóficos al que se ha dado en llamar el "giro pragmatista"; es decir, se está rescatando el pensamiento generado a principios del siglo pasado por autores como Charles Pierce, William James y John Dewey. Regularmente la filosofía del derecho se nutre y desarrolla al explorar las nuevas propuestas filosóficas que se generan en la filosofía en general. En el caso de la filosofía del derecho que se hace en la región Iberoamericana, el "giro pragmatista" no parece que este siendo tomado con la seriedad que se merece; ya que buena parte de las teorías más populares siguen asentadas en algunas formas de platonismo o siguen comprometidas seriamente con la filosofía analítica (incluso con el positivismo decimonónico). En el mejor de los casos algunos filósofos del derecho contemporáneo han adoptado algunas de las tesis del pragmatismo, pero sin molestarse en aclarar explícitamente esta filiación, salvo honrosas excepciones como es el caso de Manuel Atienza (2018). En el peor de los casos, quienes logran advertir la importancia que está tomando este movimiento de renovación, pero no simpatizan con él, simplemente se han dedicado a denostarlo, las más de las veces sin tomarse el trabajo de estudiar seriamente sus propuestas. De modo que es válido decir que para la filosofía del derecho que se hace en la región iberoamericana, el pragmatismo sigue siendo un ilustre desconocido. ${ }^{1}$

En el presente artículo me propongo esbozar algunas de los aportes que representa incorporar la perspectiva pragmatista, en particular la versión elaborada por John Dewey, en el análisis de los problemas que son discutidos en la filosofía del derecho en la actualidad. De forma indirecta, este trabajo también debe ser visto como un esfuerzo por dar a conocer el pensamiento de un autor que no es muy estudiado en nuestro entorno, explorando algunas vetas de su pensamiento que pueden aportar soluciones valiosas a los problemas jurídicos de nuestro tiempo.

Se debe tener en cuenta que la relevancia del pensamiento de John Dewey es doble. En primer lugar, porque directamente expresó consideraciones sobre cuestiones propias de la filosofía del derecho, las cuales, si bien fueron escuetas,

1 Es justo señalar que el pragmatismo tampoco ha tenido la influencia que se pudiera esperar en la tradición jurídica anglosajona. En ese sentido, se ha señalado que en sus inicios el realismo norteamericano estuvo fuertemente influido por el pragmatismo, sin embargo, para la segunda mitad del siglo la filosofía analítica consiguió establecer su hegemonía en los departamentos de filosofía de las Universidades del mundo anglosajón, relegando el pragmatismo al olvido hasta las últimas décadas del siglo pasado, dando lugar a la mencionada "Revolución pragmatista". De esta manera, autores como Brian Leiter, Jules Coleman y Richard Posner ha intentado reintroducir el pragmatismo en los estudios jurídicos de su país sin que pueda en realidad decirse que constituyan una tendencia mayoritaria. 
vale la pena que sean rescatadas debido a la innegable actualidad que conservan. En segundo lugar, debido a que los conceptos y principios filosóficos elaborados a lo largo de su vasta obra pueden constituir una valiosa herramienta en el análisis de muchos de los problemas que hoy se discuten en la filosofía del derecho, en particular en los países de tradición europea continental, como es el caso de los países latinoamericanos. A continuación, a fin de perfilar con más detalle estas dos aseveraciones, se exponen algunas consideraciones generales (históricas y filosóficas) sobre el pensamiento de John Dewey.

\section{BREVE SEMBLANZA BIOGRÁFICA Y FILOSÓFICA DE JOHN DEWEY}

El pragmatismo es una corriente filosófica que tuvo su origen en los Estados Unidos a finales del siglo XIX y se desarrolló a lo largo de la primera mitad del siglo XX. Sus exponentes más destacadas fueron Charles Sanders Pierce, William James y John Dewey. Si bien es cierto que las tesis formuladas por estos tres filósofos pueden estar baste distanciadas entre sí, lo cierto es que guardaban ciertas afinidades que permitieron considerarlas como parte de una misma tendencia dentro de la historia de las ideas; al grado que se les considera como la primera escuela filosófica surgida en los Estados Unidos. Durante ese periodo el prestigio e influencia del pragmatismo en su país de origen fue innegable, no sólo en los círculos académicos universitarios, sino también en muchos aspectos de la vida pública. No obstante, después de la Segunda Guerra Mundial la migración de filósofos europeos a las universidades estadounidenses provocó que la filosofía analítica se convirtiera en el modo filosófico dominante. Como resultado el pragmatismo fue relegado al olvido. Por su parte, en los países de tradición filosófica continental el pragmatismo nunca causo impacto significativo, y la poca atención que se le dispensó fue por lo general para hacerle mala prensa. ${ }^{2}$

Fue sólo hasta las últimas décadas del siglo pasado cuando filósofos de la talla de Richard Rorty, Hilary Putnam y Richard Bernstein desarrollaron sendos esfuerzos para rehabilitar el pragmatismo, en particular en la versión instrumentalista elaborada por John Dewey. Sus esfuerzos han sido exitosos a tal grado que se ha dado en afirmar la existencia de un "giro naturalista o giro pragmatista" en la filosofía contemporánea. De hecho, a decir de Rorty, Dewey debe ser considerado, junto con Heidegger y Wittgenstein, como uno de los tres filósofos más importantes del siglo XX. ${ }^{3}$

2 No obstante, es necesario señalar que buena parte de las traducciones disponibles en castellano se editaron a mediados del siglo XX en México y en Argentina. Me refiero a obras como Lógica Teoría de la Investigación (1950), En busca de la Experiencia y educación (1943), Democracia y educación (1946), Libertad y cultura (1946), La busca de la certeza (1952), Naturaleza humana y conducta (1964), La experiencia y la naturaleza (1948) y El arte como experiencia (1949). Se tuvo que esperar hasta el final de siglo, en pleno giro pragmatista, para que nuevas traducciones comenzaran a editarse en España y México.

3 Lo cierto es que al igual que en el caso de los otros dos integrantes de la triada mencionada (Heidegger y Wittgenstein), el pensamiento de Dewey representa un intento por renovar la filosofía tal como se había hecho hasta principios del siglo XX, empresa en la que, una vez más citando a Rorty, sus teorías han demostrado haberse adelantado y en muchos sentidos superar a las teorías de los filósofos de finales del siglo XX. 
Dewey nació en Burlington, Vermont, en 1859 y murió en Nueva York en 1952. En 1884 se doctoró en la Universidad Johns Hopkins. Poco después se incorporó como profesor en la Universidad de Chicago y después se trasladaría a la Universidad de Nueva York, en donde permanecería hasta su retiro; lo cual de ninguna manera significó que dejara su trabajo como escritor, ya que literalmente se mantuvo trabajando hasta el día de su muerte.

Dewey fue conocido también por ser un educador revolucionario; de hecho, durante mucho tiempo fue más recordado por sus contribuciones a la pedagogía que a la filosofía. En la Universidad de Chicago echó a andar una escuela experimental para niños, en la que puso en práctica muchas de sus teorías pedagógicas. ${ }^{4}$ Fue llamado a países como China, Japón Rusia o México para dictar conferencias sobre sus ideas pedagógicas y para supervisar la puesta en marcha de escuelas modelo en las que se utilizaron sus propuestas. Además, fruto de su convencimiento de que la teoría y la práctica no deberían ser consideradas como dos cosas separadas, Dewey participó activamente en apoyo a diversos grupos defensores de derecho civiles.

En la época en la que John Dewey realizó sus estudios doctorales, dominaba en la Universidad Johns Hopkins un ambiente hegeliano, por esta razón en sus primeros trabajos es posible advertir una clara influencia de este filósofo; no obstante, esta se diluyó hasta mantener sólo el marcado sentido de la contextualización histórica que el propio pragmatismo exige. Pero cuando Dewey entró en contacto con la teoría de la evolución de Charles Darwin, esta se constituyó en su principal egida, de la cual tomaría las bases naturalistas que caracterizaron el resto de su trabajo.

Filosóficamente el naturalismo es una postura que rechaza cualquier explicación metafísica o supraempírica para los problemas de la filosofía, de la ciencia o de la vida en general; en consecuencia, asume como plausibles sólo las consideraciones que se desprenden de la experiencia. En este punto conviene aclarar que para el naturalismo las manifestaciones mentales y culturales son empíricamente observables al igual que la materia y la energía de las que se compone el universo. En el caso de John Dewey, este rechazo de las explicaciones supraempíricas es la nota distintiva a partir de la cual logra realizar aportaciones originales y significativas en todas las disciplinas filosóficas; esto es, en la ontología, la epistemología, la estética, la lógica, la ética y la filosofía política.

Sin duda, no es este el lugar indicado para hacer una exposición ni siquiera mínima de cada una de las parte de su sistema filosófico, sin embargo, sí es conveniente al menos mencionar algunos de las notas que le identifican como pensador original; a) el rechazo a los dualismos metafísicos generados por las filosofías idealistas, b) el empirismo cientificista, c) un historicismo no determinista, d) la insistencia más en las consecuencias que en las causas, y e) la elaboración de conceptos clave como experiencia, inteligencia, transacción y valoración.

4 Además, se considera que como consecuencia de la impronta que ejerció en la Universidad de Chicago se formó la escuela de economistas conocida como "La escuela de Chicago". Si bien esto pudo ser cierto en los inicios de la Escuela de Chicago, bien pronto la influencia de la filosofía analítica substituiría el influjo pragmatista. Lo mismo sucedería con el Realismo Jurídico. 
El primero punto mencionado se refiere a la aversión que Dewey mostraba hacia los muchos dualismos que se observan en la filosofía accidental quizá desde sus orígenes. El más persistente de ellos precisamente aquel mediante el cual se distingue entre un mundo empírico al que se accede por los sentidos, y otro supraempírico, que no es posible percibir a través de los sentidos. Para Dewey este dualismo ontológico no sólo es erróneo, sino que ha distorsionado la manera en la que se abordan los problemas filosóficos, ya que se replica en todas las demás áreas de la filosofía.

En consecuencia, el pragmatismo, también llamado naturalismo o instrumentalismo (Dewey prefería estas denominaciones a la de pragmatismo) es una postura empirista. Asumir con seriedad el empirismo requiere que se disponga de un método adecuado para poder hacerse con la información necesaria que permita conocer el mundo. Como resultado de una marcada influencia darwiniana, Dewey considera que el método de las ciencias es el mejor procedimiento del que dispone la humanidad para entender y manipular el mundo que le rodea y desde su punto de vista no existe impedimento para que dicho método pueda utilizarse en todas las demás áreas del conocimiento. En este punto es importante hacer notar que Dewey se haya lejos de asumir un cientificismo ingenuo, y que estaba consciente de que éste método debe ajustarse dependiendo de los problemas a los que se desea hacer frente; lo cual, por otra parte, es algo que de hecho se hace en la práctica científica cotidiana.

El empirismo exige que los problemas se analicen en su contexto, es decir, con conciencia histórica. El historicismo elaborado por John Dewey no es determinista, pues no considera que exista una finalidad predeterminada en el devenir histórico, como es el caso de los historicismos hegeliano y marxista. Dewey considera que las personas pueden intervenir en el desarrollo de los hechos futuros, ya sea para mejorar o para empeorar las situaciones y condiciones actuales. En todo caso, es responsabilidad de las personas y de las sociedades deliberar de forma inteligente a fin de discernir las posibles consecuencias en los cursos de acción que adopten, y elegir de la forma más adecuada en cada caso, haciendo uso de las mejores fuentes de información de las que se disponga.

La importancia que le reconoce Dewey al conocimiento empírico lo lleva a elaborar (y adoptar) los conceptos de experiencia, inteligencia, transacción y valoración como ejes conceptuales a partir de los cuales se desarrolla su sistema filosófico. Desde su punto de vista la experiencia es la percepción misma que se genera como consecuencia de estar en el mundo; de forma más específica, la forma a través de la cual nos hacemos con la información para poder existir. Para Dewey esta apreciación es válida para todos los aspectos de la vida de las personas, y aplica tanto para la vida cotidiana como para las investigaciones científicas más sofisticadas. Ahora bien, de acuerdo con nuestro autor, el estar en el mundo, es decir, la convivencia con el entorno, no genera nunca relaciones de un solo sentido, sino que son relaciones de ida y vuelta; en su vocabulario, se puede decir que las personas, y hasta las cosas, llevan a cabo constantemente una serie transacciones con su entorno. 
Adquirir experiencias equivale a realizar transacciones con el entorno, pero a diferencia de los animales o de las cosas, el ser humano tiene conciencia de que dichas transacciones ocurren; de manera que intencionalmente provoca buena parte de las transacciones en las que se ve involucrado. En otras palabras, decide que algunas transacciones tengan lugar y no otras. Esto es, el ser humano continuamente ejecuta procesos de valoración, de elección racional entre diferentes cursos de acción, tasando las posibles consecuencias. Este proceso de valoración presupone una capacidad intelectual que Dewey denominó inteligencia, entendida como una capacidad evolutiva propia de los seres humanos, que les permite obtener ventajas de forma consciente de las transacciones con su entorno. La inteligencia, implica necesariamente la racionalidad, pero a diferencia de la noción ilustrada de Razón, la inteligencia no es absoluta ni tampoco infalible.

En el caso de los seres humanos, las transacciones en que se involucra tienden a modificar el medio en que se encuentra, constituyendo lo que conocemos como vida social; la cual es el lugar desde donde desarrollamos la gran mayoría, por no decir todas, las transacciones que realizamos en el mundo. Por esta razón, la ética y la política tienen un lugar privilegiado en el sistema filosófico de John Dewey. Y como no podría ser de otra manera, todo ello tiene derivaciones relevantes para una teoría jurídica de corte pragmatista.

Para el caso de la filosofía del derecho, en la obra de John Dewey existen múltiples vetas en las cuales se puede explorar; sin embargo, a continuación, me gustaría resaltar sólo tres de ellas. La primera, es la que ofrecen dos breves artículos en los que el autor se ocupa directamente de problemas típicos de filosofía del derecho, estos son "Logic Method and Law" [1925] y "My Philosophy of Law" [1941]. La segunda veta es la teoría ética elaborada por John Dewey, específicamente en sus obras Teoría de la valoración (2012 [1939]) y Teoría de la vida moral (1965 [1932]). Por último, me referiré a la constante preocupación que John Dewey mostró a lo largo de su obra por la democracia, la libertad y los derechos; cuestiones que, si bien son consideradas como parte central de su filosofía política, también constituyen temas torales para la filosofía del derecho contemporánea.

\section{LA FILOSOFÍA DEL DERECHO EN LA OBRA DE JOHN DEWEY}

Los dos artículos que John Dewey dedicara a tratar cuestiones típicamente consideradas como parte de una filosofía del derecho fueron producidos en momentos diferentes de su carrera, con alrededor de tres lustros de distancia entre uno y otro; no obstante, en ambos casos se aprecia claramente el empirismo y el rechazo a los dualismos, líneas generales de pensamiento que subyacen en toda su obra.

El primero de ellos, "Logic Method and Law" fue publicado en 1925 y puede ser leído de dos maneras; en primer lugar, como una formulación preliminar de algunas ideas que después se convertirían en una de las obras mayores del autor, me refiero a su Lógica, teoría de la investigación (1959 [1938]); y la segunda, que es la que interesa aquí, como una breve exposición de una teoría de 
la interpretación jurídica. El objetivo que tiene Dewey en este artículo es hacer notar la imposibilidad de que el tradicional método de la subsunción jurídica realmente sirva como método para la aplicación de las normas jurídicas; al tiempo, realiza un análisis de la forma en la que, a consideración suya, se lleva a cabo el razonamiento jurídico, análisis que de hecho puede ser entendido como la propuesta de un método pragmatista de interpretación jurídica.

Como es bien sabido, en las últimas décadas el problema de la interpretación de las normas jurídicas ha estado en el centro del debate de la filosofía del derecho, tanto en la tradición continental como en la del Common Law. Ronald Dworkin, Robert Alexy, Luigi Ferrajoli, y en el entorno iberoamericano Manuel Atienza, probablemente son los autores que más han hecho por el estado de la cuestión en la actualidad. En este momento histórico, en el que los derechos constitucionalmente reconocidos ocupan un lugar preponderante en los sistemas jurídicos, existe no obstante una serie de dudas respecto a cuál es la naturaleza de estas normas constitucionales, cómo se aplican y cómo interactúan con otras normas jurídicas. Una de las notas comunes de las teorías contemporáneas de la interpretación jurídica es la consideración de que el modelo tradicional de la subsunción no sirve para explicar la forma en la que se aplican las normas jurídicas, especialmente en el supuesto de los llamados "casos difíciles".

En la época en la que Dewey escribiera este ensayo el positivismo jurídico era la teoría dominante en la filosofía del derecho y no se discutía acerca de la distinción entre las reglas y los principios. Esto explica el interés que tuvo Dewey en enfilar sus críticas en contra de la tesis del silogismo jurídico; sin embargo, la justificación empírica (psicológica) del razonamiento jurídico proporcionada por este autor da cuenta, mejor que las teorías contemporáneas arriba mencionadas, no sólo de la interpretación de los casos aparentemente regidos sólo por reglas, sino también los casos en los que tienen que ver normas tipo principios.

De acuerdo con Dewey el silogismo jurídico no es sino una manera elegante de presentar la solución de un problema una vez que esta ha sido hallada. Para él, la solución de los problemas jurídicos, al igual que los problemas morales, requiere de un proceso en el que conforme se avanza en el conocimiento de los hechos se avanza también en la determinación de las normas que habrán de ser aplicadas. Se trata de un procedimiento mental único y no de dos procesos distintos que se puedan llevar por cuerda separada. De este modo, sólo hasta que se tiene una respuesta al problema jurídico de que se trate, es que el operador está en condiciones de expresarla. Que la tradición haya impuesto hacerlo a través del modelo silogístico es cuestión aparte.

Debido a la brevedad del artículo Dewey no ofrece mayores detalles sobre el método de investigación que propone; sin embargo, ya que para Dewey el mismo método de indagación puede ser aplicado tanto para las investigaciones científicas, como para las filosóficas y las jurídicas, es posible desprender mayores consideraciones de otras de sus obras; en particular de su Lógica. Teoría de la investigación (1950), obra en la que de hecho desarrolla algunas de las ideas expresadas en germen en "Logic Method and Law" (1925). 
En “My Philosophy of Law", publicada en 1947, Dewey se ocupa de uno de los problemas clásicos de la filosofía del derecho, me refiero al debate entre el iusnaturalismo y el iuspositivismo. Que el filósofo norteamericano se propusiera analizar este tema no es casualidad. Debe tomarse en cuenta que al final de la Segunda Guerra Mundial las teorías iusnaturalistas estaban en auge y en franca confrontación con el iuspositivismo que dominaba desde finales del siglo XIX la filosofía del derecho.

En este breve artículo Dewey comienza por establecer que, para él, el derecho es un fenómeno enteramente social en el sentido de que las normas jurídicas surgen en el seno de la vida social y no nos vienen de ningún universo normativo ideal. Congruente con la vocación sociológica de su filosofía, Dewey se percató de que el derecho no puede ser concebido de forma reduccionista, es decir, para este autor la palabra derecho es utilizada para señalar un grupo muy grande de actividades sociales, las cuales son consideradas por las personas que intervienen en ellas como provistas de una obligatoriedad especial propia de las cuestiones jurídicas. Desde la postura de John Dewey, la razón de que el derecho haya sido considerada como una noción difícil de definir, reside justamente en la variedad de actividades que pueden tener una connotación jurídica; en consecuencia, tiene más significado ocuparnos de las situaciones en las que surge y se aplica el derecho, que de la posibilidad de reducir todas esas situaciones a una sola formula definicional.

Siendo que Dewey entiende el derecho como una variedad amplia de transacciones sociales, debemos señalar que acepta una noción por entero empírica de lo jurídico, con lo cual se desliga de cualquier consideración iusnaturalista, en particular del dualismo conforme al cual el mundo normativo se divide entre las normas del derecho positivo y las normas ideales que surgen de la naturaleza humana ideal, la razón absoluta o la revelación divina. Lo que de ninguna manera equivale a desestimar la validez de las pretensiones iusnaturalistas, pues para Dewey es esencial que podamos disponer de un parámetro conforme al cual valorar la legitimidad de las normas de derecho que rigen la vida social. De esta manera, Dewey se desliga también de las tesis iuspositivistas que postulan como legitimas a las normas jurídicas sólo por haber sido creadas por las instancias y a través de los procedimientos legales correspondientes.

Desde el pragmatismo de John Dewey una de las funciones principales de la filosofía del derecho consiste en indagar en relación a los estándares bajo los cuales podemos tener a las normas jurídicas como legítimas, sólo que estos parámetros tienen que tener un referente empírico y no podemos pensar que pueden ser construidos a partir de fundamentos ideales o supraempíricos, sean cuales sean. Por esta razón, para Dewey la filosofía del derecho debe ser vista como una crítica permanente de los sistemas jurídicos. Por supuesto, este es un programa que también adoptan las teorías iusnaturalistas, pero el problema con estas es que admiten como absolutos e incontrovertibles ciertos principios últimos, con lo cual, los estándares que todas ellas proponen terminan por anquilosarse y dejan de responder a las necesidades sociales. 
En este punto es conveniente remitir la Teoría de la valoración (2012), conforme a la cual, respecto de cualquier situación en la que deban tomarse decisiones, lo adecuado es hacerlo teniendo en cuenta las condiciones específicas de cada caso; y esto es válido también para los problemas de corte jurídico. En otras palabras, en congruencia con su postura instrumentalista, Dewey considera que el mejor parámetro para la valoración de las normas jurídicas es el conocimiento de las situaciones en las cuales se pretende incidir con la norma y de los efectos que estas generan en esas mismas situaciones.

\section{LA TEORÍA DE LA VALORACIÓN DE JOHN DEWEY Y LAS RELACIONES ENTRE DERECHO Y MORAL}

Como ya se ha comentado, en la obra de John Dewey lo que él denominaba vida moral tiene un lugar central, esto es así ya que para Dewey la vida moral está conformada por todos los comportamientos humanos, por las elecciones que realizamos todos los días; de manera que no sólo las grandes decisiones que pueden afectar seriamente nuestras vidas son objeto de la teoría ética del filósofo norteamericano. Lo anterior de ninguna manera significa que este autor no estuviera consciente de que algunas decisiones son más trascendentes que otras, simplemente que el método que desde su punto de vista sirve para que el hombre común tome decisiones en su vida diaria es, de hecho, el mismo que puede permitirnos resolver las cuestiones más relevantes de nuestra vida social, sólo que en este último caso conviene afinar dicho método.

A esta tarea John Dewey le dedico numerosos artículos y algunos libros en los que trata de manera sistemática la cuestión. Me refiero a su Teoría de la vida moral (1965), Naturaleza humana y conducta (1975 [1922]), y Teoría de la valoración (2012). En todos ellos Dewey ofrece abundantes aristas que podrían ser desarrolladas en una filosofía pragmatista del derecho, sin embargo, en este momento quisiera centrarme en su Teoría de la valoración, obra de madurez en la que el autor expone de manera suscitan las principales tesis de su filosofía moral, las cuales pueden ser llevadas al terreno de la filosofía del derecho.

En Teoría de la valoración (2012) Dewey expone una postura instrumentalista sobre las normas morales con la que pretende distanciarse de las teorías idealistas de la moral, por un lado, y del emotivismo ético, por otro. El idealismo ético se caracteriza por considerar que existen normas morales absolutas, válidas en todo lugar y tiempo, las cuales son cognoscibles por Revelación o a través de la Razón (absoluta). Por su parte el escepticismo ético niega la posibilidad de que las normas morales sean susceptibles de conocimiento racional, a lo mucho, las considera simples expresiones emotivas e irracionales. ${ }^{5}$

Bajo este marco de referencia, contrario a lo sostenido por el escepticismo, el instrumentalismo ético propuesto por Dewey considera que los valores morales son objeto de conocimiento racional; y a diferencia de lo que sostienen los idealismos, para Dewey los valores morales no son absolutos, ya que no nos bajan

5 Por esta razón a esta tesis también se le conoce como emotivismo ético. 
“de ningún Monte Sinaí”; es decir, no son cuestiones metafísicas sino fruto de la experiencia. Puesto que tanto las normas morales como las jurídicas surgen de una determinada realidad y se aplican a situaciones de hecho concretas, en esa misma medida pueden ser objeto de discusión, e incluso de experimentación. Desde la teoría moral de John Dewey los valores son cuestiones empíricas, hechos observables y tasables al igual que la masa y el movimiento de los cuerpos. De esta manera, pierde sentido hablar de una supuesta "falacia naturalista" en la discusión de las normas y los valores.

El idealismo es una de las características que distingue a todas las teorías iusnaturalistas, mientras que el escepticismo es una de las notas que distinguen a las teorías iuspositivistas. Visto así, el pragmatismo representa una alternativa para superar una disputa que parece ocupar todo el espectro de la filosofía del derecho. Por esta razón valdría la pena que en los países de tradición jurídica continental pudiera asumirse con seriedad una propuesta como la que ofrece el pragmatismo ético. Además, se debe reconocer que en los sistemas de tradición romanistas es cada vez mayor la relevancia que se le otorga a la moral, por lo que debiéramos ser capaces de explicar de forma racional las relaciones que se establecen entre estos dos universos normativos, sin recurrir a trasnochados idealismos, ni a escepticismos ya rebasados.

\section{DEMOCRACIA, LIBERTAD Y DERECHOS EN EL PENSAMIENTO DE JOHN DEWEY}

Incluso en vida John Dewey ya era considerado como el filósofo de la democracia, lo cual no es gratuito si se toma en cuenta la constancia con la que se ocupó del tema, sobre todo en multitud de artículos cortos, muchos de los cuales fueron publicados en periódicos y revistas de circulación masiva. Por supuesto, también le dedicó varios libros y ensayos largos en los que también analiza cuestiones sobre teoría política, la libertad y los derechos civiles. Se trata de obras como, por ejemplo: El público y sus problemas (2004 [1927]), Viejo y nuevo individualismo (2003), Liberalismo y acción social (1999 [1935]), y Educación y democracia (2004a).

Para Dewey la democracia en el único medio en el que la libertad y el ejercicio de derechos son posibles. En no pocas ocasiones se le acusó de asimilar la democracia a la democracia norteamericana; sin embargo, es esta una más de las acusaciones gratuitas que de continuo se enderezan en su contra, ya que en realidad fue uno de los críticos más acérrimos del sistema político estadounidense, y todavía hoy sus tesis son utilizadas para criticar las condiciones de la vida pública en aquel país. Conviene hacer notar que para Dewey la democracia no se limita a ser una forma de gobierno, sino que representa la forma deseable en la que deberían conducirse las personas en sus interacciones sociales; no sólo en relación a las instituciones gubernamentales, sino también en instituciones como la escuela o la familia. 
Para Dewey la democracia es una forma de vida, y para que un país pueda ser considerado como democrático no basta con que se celebren elecciones periódicas, sino que además es necesario que las personas puedan ejercer su capacidad de autodeterminación en todas las transacciones sociales en las que intervienen. Esta postura, lejos de fomentar el individualismo en realidad presupone la existencia de sólidos mecanismos de comunicación interpersonal. Esto es así porque las personas nunca ejercer su capacidad de autodeterminación en solitario, sino como parte de las transacciones que establecen con otras personas. Dicho de otro modo, para que el ejercicio de autodeterminación de uno no se convierta en imposición para otro, es necesario que se discutan las opciones y se adopten acuerdos a través de mecanismos democráticos. En este sentido es que se ha dicho que la teoría de la vida democrática de John Dewey se anticipa a la tesis habermasiana de la acción comunicativa, ${ }^{6}$ pero sin recurrir a la veta idealista en que se fundamenta la obra del profesor alemán.

En algunos artículos extensos como "Liberalismo y acción social” y la serie de escritos compendiada en "Viejo y nuevo liberalismo", Dewey se ocupa de uno de los problemas que aún hoy día consideramos cruciales, me refiero al del tamaño del Estado y las exigencias que los ciudadanos pueden hacer valer en su contra. Como ya se comentó líneas arriba, Dewey fue crítico no sólo de los muchos dualismos que se pueden encontrar en la literatura filosófica; además, fue enemigo de todo tipo de absolutismos dogmáticos, sean estos del signo que sean. En ese sentido, Dewey percibió claramente que en la época en la que le tocó vivir, en los Estados Unidos existía una especie de fanatismo en relación con las teorías liberales clásicas, las cuales eran tenidas por sus defensores prácticamente en calidad de autos de fe.

Por supuesto, Dewey se está refiriendo a la disputa política que todavía se puede observar en la vida pública de aquel país (y en muchos otros países occidentales) entre quienes defienden una versión conservadora de las teorías liberales y aquellos otros que proponen nociones liberales pero de corte más social. Los primeros son partidarios de un Estado mínimo y consideran como derechos exigibles únicamente los derechos negativos o derechos humanos de primera generación. Los segundos en cambio, son partidarios de un Estado con más responsabilidad social y proclaman como derechos exigibles una serie de prestaciones relacionadas con el trabajo, la salud y la educación; cuestiones que en la nomenclatura de Vasak son denominadas como derechos humanos de segunda generación o derechos económicos y sociales. Para los liberales conservadores, los derechos económicos y culturales representan injerencias injustificables del Estado en la vida de los particulares; en cambio, para el liberalismo de corte social, representan obligaciones ineludibles.

En "Liberalismo y acción social” Dewey se propone demostrar que cuando se entiende al liberalismo clásico como un producto acabado, se vuelve dogmático y eso le convierte en una propuesta anquilosada. Lo que Dewey sostiene es

6 No obstante, una de las críticas que suelen hacerse al autor alemán es que no reconoce la influencia pragmatismo, en particular deweyana, que se observa en sus obras. 
que si en su tiempo el liberalismo clásico pudo pensarse como la mejor propuesta de filosofía política en función de los problemas a los que debió hacer frente; en la actualidad, para que pueda seguir cumpliendo con sus promesas de libertad, es necesario que se actualice conforme a las condiciones de esta época; lo que para Dewey significa dotar al liberalismo de una buena dosis de conciencia social a favor de las clases desfavorecidas por el desarrollo económico desigual.

Debido a estas propuestas Dewey fue tenido en vida como un autor de tendencias socialistas; no obstante, las luchas ideológicas en torno a los problemas a los que Dewey se refiere continuaron a lo largo del siglo pasado, y aún hoy estas tensiones provocan que cíclicamente se impongan políticas de corte más conservador (neoliberal) o más progresista, según sea el caso. Por esta razón el análisis de la obra de John Dewey sigue teniendo vigencia y puede ayudarnos en el fortalecimiento de los derechos sociales y los derechos de tercera generación; sobre todo en la actualidad, cuando todavía algunos sectores conservadores les consideran como simples propuestas ideológicas y no como exigencias legales pendientes de cumplir.

\section{CONSIDERACIONES FINALES}

En la filosofía del derecho que se hace en los países iberoamericanos el pragmatismo resulta ser casi un ilustre desconocido; no obstante, esta situación es reflejo de la poca difusión que tuvo esta teoría filosófica en el ámbito de influencia de los países europeos continentales, cómo es la región latinoamericana. Escasa difusión que en no pocas ocasiones ha sido acompañada de abiertas cruzadas de desprestigio. Esta situación ha cambiado en las últimas décadas del siglo pasado, y ha surgido la consideración de que el pragmatismo, en particular, la versión elaborada por John Dewey puede proveernos de mejores soluciones a los problemas filosóficos contemporáneos, de las que nos han provisto otras ofertas teóricas, incluso las más recientes.

A partir de esta consideración, vale la pena explorar las posibilidades que el pragmatismo ofrece en relación a los problemas de los que se ocupa la filosofía del derecho. Operaciones de este tipo son frecuentes en la filosofía del derecho, y de hecho es el método que se ha mostrado más efectivo para lograr avances en determinados problemas que las posturas dominantes no alcanzan a resolver de forma satisfactoria; también ha sido la forma en encontrar nuevas vetas de investigación y desvelar nuevos problemas de los cuales se debe ocupar esta disciplina.

Las vetas que se han sugerido en este trabajo para aprovechar el trabajo filosófico de John Dewey son sólo ejemplos de las puede ofrecer. Se trata quizá de las que de forma más obvia surgen de un primer acercamiento a la obra de este filósofo norteamericano. Se debe tener en cuenta que la suya es una obra extensa y las posibilidades directas o indirectas pueden ser muchas más. Sin embargo, siguiendo el espíritu pragmatista, quizá la tarea más significativa, pero más complicada, es la de hacerse con las herramientas pragmatistas y utilizarlas para el análisis de los problemas que nos impone el entorno actual y no indagar con un 
mero espíritu de anticuario en una obra filosófica que como tal respondió a los problemas de su tiempo; la cual no obstante, sigue vigente en muchos sentidos.

Hoy en día las condiciones globales han hecho surgir fuertes sentimientos populistas antidemocráticos en una época en la que se consideraba que el predominio de los valores democráticos era incuestionable. Por esta razón, quizá la vertiente más provechosa que se puede obtener del pensamiento de John Dewey sea la que se ofrece en su teoría de la vida democrática. Para John Dewey la democracia no era algo que se pudiera alcanzar de una vez y para siempre, sino que era una cuestión que exige constante atención. En este sentido, posiblemente el recurso al pragmatismo pueda producir nuevas perspectivas que complementen las que se han generado por la filosofía del derecho contemporánea. Espero este trabajo sirva como una invitación en este sentido. Si por algo se distingue la filosofía del derecho en la actualidad en por comprender que el derecho, la política y la moral no son entidades separadas, y que si pretendemos comprender alguna de ellas (en este caso el derecho) conviene tener siempre presentes a las otras. Esta es una de las enseñanzas y razones por las que conviene estudiar una obra como la del autor de referencia.

\section{BIBLIOGRAFÍA}

ATIENZA, Manuel (2018) "Pragmatismo jurídico: la propuesta de Susan Haack", Estudios Filosóficos, vol. 67, núm. 196, pp. 467-489.

DEWEY, John (1925) Logic Method and Law, versión electrónica disponible enhttp://heinonline.org

DEWEY, John (1948) [1925] La experiencia y la naturaleza, trad. José Gaos, Fondo de Cultura Económica, México.

DEWEY, John (1950) [1938] Lógica. Teoría de la Investigación, trad. Eugenio Imaz, Fondo de Cultura Económica, México.

DEWEY, John (1952) [1929] La busca de la certeza, trad. Eugenio Imaz, Fondo de Cultura Económica, México.

DEWEY, John (1965) [1932] Teoría de la Vida Moral, Ed. Herrero Hermanos, México.

DEWEY, John (1975) [1922] Naturaleza humana y conducta. Introducción a la filosofía social, Fondo de Cultura Económica, México.

DEWEY, John (1993) La reconstrucción de la filosofia, trad. Amando Lázaro Ros, Planeta-De Agostini, Barcelona.

DEWEY, John (1995) [1916] Democracia y educación, Madrid, Ediciones Morata.

DEWEY, John (1999) [1935] Liberalism and Social Action, New York, Prometheus Books.

DEWEY, John (2000) [1909] "La influencia del darwinismo en la filosofía", en DEWEY, John, La miseria de la epistemología, ed. y tr. de Angél Manuel Faerna, Madrid, Ed. Biblioteca Nueva.

DEWEY, John (2004) [1927] La opinión pública y sus problemas, Ed. Morata, Madrid.

DEWEY, John, (2004a) Democracia y educación, Ed. Morata, Madrid. 
DEWEY, John (2011) John Dewey. Selección de textos, tr. Diego Antonio Pineda Rivera, Medellín, Colombia, Universidad de Antioqía.

DEWEY, John (2012) [1939] Teoría de la Valoración, trad. Jaime Fisher y Salazar, Bogotá, Ed. Uniminuto.

DEWEY, John (2013) [1941] "Mi filosofía del derecho" en Revista de Derecho Privado, núm. 24, enero junio de 2013, pp. 337-343, Universidad Externado de Colombia, tr. Alberto Supelano y Pablo Moreno Cruz. Disponible en www. scielo.org.co/scielo

DWORKIN, Ronald (1993a) Los derechos en serio, Barcelona, Planeta-Agostini. DWORKIN, Ronald (1992) El imperio de la justicia, Barcelona, Gedisa.

FINNIS, John, Ley natural y derechos naturales, Buenos Aires, Abeledo-Perrot. HABERMAS, Jürgen (2010a) Facticidad y Validez. Sobre el derecho y el Estado democrático de derecho en términos de teoría del discurso, Madrid, Trotta.

HABERMAS, Jürgen (2008) "Valores y normas. Un comentario al pragmatismo kantiano de Hilary Putnam" en PUTNAM, Hilary y HABERMAS, Jürgen, Normas y Valores, Madrid, Ed. Trotta, pp. 79-106.

HART, H.L.A. (2009) El concepto de derecho, Buenos Aires, Abeledo-Perrot.

HELD, David (1997) La democracia y el orden global. Del estado moderno al gobierno cosmopolita, Barcelona, Paidós.

HOOK, Sidney (2000) [1939] John Dewey. Semblanza Intelectual, Barcelona, Paidós.

JACKSON, Philip W. (2004) John Dewey y la tarea del filósofo, Buenos Aires, Amorrourtu.

LEITER, Brian (2012) Naturalismo y teoría del derecho, Madrid, Marcial Ponds. MOUGAN Rivero, Juan Carlos (2000) Acción y racionalidad. Actualidad de la Obra de John Dewey, Cádiz, Servicio de Publicaciones de la Universidad de Cádiz.

PUTNAM, Hilary "Valores y normas", en PUTNAM, Hilary y HABERMAS, Jürgen, Normas y Valores, Madrid, Trotta, pp. 50-78.

PUTNAM, Hilary y PUTNAM, A. (1997) "La lógica de Dewey: epistemología como hipótesis", en Hilary Putnam, La herencia del pragmatismo, Barcelona, Paidós.

PUTNAM, Ruth Anna (1988) "La unidad del hecho y el valor", en VILLANUEVA, E. (comp.), III Simposio Internacional de Filosofia, t. II, México, UNAM. RORTY, Richard (1998) Truth and progress. Philosophical Papers v. 3, New York, Cambridge University Press. Versión castellana Verdad y progreso: escritos filosóficas v. 3, Barcelona, Paidós. 